\title{
Exploring perspectives of young onset dementia caregivers with high versus low unmet needs
}

Citation for published version (APA):

Millenaar, J. K., Bakker, C., van Vliet, D., Koopmans, R. T. C. M., Kurz, A., Verhey, F. R. J., \& de Vugt, M. E. (2018). Exploring perspectives of young onset dementia caregivers with high versus low unmet needs. International Journal of Geriatric Psychiatry, 33(2), 340-347. https://doi.org/10.1002/gps.4749

Document status and date:

Published: 01/02/2018

DOI:

10.1002/gps.4749

Document Version:

Publisher's PDF, also known as Version of record

Document license:

Taverne

Please check the document version of this publication:

- A submitted manuscript is the version of the article upon submission and before peer-review. There can be important differences between the submitted version and the official published version of record.

People interested in the research are advised to contact the author for the final version of the publication, or visit the DOI to the publisher's website.

- The final author version and the galley proof are versions of the publication after peer review.

- The final published version features the final layout of the paper including the volume, issue and page numbers.

Link to publication

\footnotetext{
General rights Owners
rights.

- You may freely distribute the URL identifying the publication in the public portal. please follow below link for the End User Agreement:

www.umlib.nl/taverne-license

Take down policy

If you believe that this document breaches copyright please contact us at:

repository@maastrichtuniversity.nl

providing details and we will investigate your claim.
}

Copyright and moral rights for the publications made accessible in the public portal are retained by the authors and/or other copyright owners and it is a condition of accessing publications that users recognise and abide by the legal requirements associated with these

- Users may download and print one copy of any publication from the public portal for the purpose of private study or research.

- You may not further distribute the material or use it for any profit-making activity or commercial gain

If the publication is distributed under the terms of Article $25 \mathrm{fa}$ of the Dutch Copyright Act, indicated by the "Taverne" license above, 


\title{
Exploring perspectives of young onset dementia caregivers with high versus low unmet needs
}

\author{
Joany K. Millenaar ${ }^{1}$ (D), Christian Bakker ${ }^{2,3}$, Deliane van Vliet $^{3}$, Raymond T.C.M. Koopmans ${ }^{3,4}$, Alexander Kurz ${ }^{5}$, \\ Frans R.J. Verhey ${ }^{1}$ and Marjolein E. de Vugt $^{1}$ \\ ${ }^{1}$ School for Mental Health and Neuroscience, Alzheimer Center Limburg, Maastricht University Medical Center, Maastricht, The \\ Netherlands \\ ${ }^{2}$ Florence, Mariahoeve Center for Specialized Care in Young-Onset Dementia, Den Haag, The Netherlands \\ ${ }^{3}$ Department of Primary and Community Care: Center for Family Medicine, Geriatric Care and Public Health, Radboudumc Alzheimer \\ Centre Nijmegen, Radboud University, Nijmegen, The Netherlands \\ ${ }^{4}$ Joachim en Anna Center for Specialized Geriatric Care, Nijmegen, The Netherlands \\ ${ }^{5}$ Department of Psychiatry and Psychotherapy, Klinikum rechts der Isar, Technische Universität München, Munich, Germany \\ Correspondence to: M. de Vugt, E-mail: m.devugt@maastrichtuniversity.nl
}

Background: This study is part of the Research to Assess Policies and Strategies for Dementia in the Young project. Information about specific needs in young onset dementia (YOD) will provide the basis for the development of an e-health intervention to assist caregivers in coping with YOD in several European countries.

Objective: The aim was to investigate the issues caregivers of people with YOD face.

Methods: A qualitative content analysis method was used to analyse interviews with YOD caregivers. Quantitative data of the Needs in Young Onset Dementia study were used to select caregivers based on a ranking of unmet needs, to capture differences and similarities between caregivers that experienced high levels of unmet needs versus those with low levels of unmet needs. Needs were assessed with the Camberwell Assessment of Needs in the Elderly.

Results: Findings revealed the following themes: (i) acceptance; (ii) perception of the relationship; (iii) role adaptation; (iv) Availability of appropriate services; (v) social support; and (vi) awareness in the person with dementia and acceptance of help. Several factors seemed more apparent in the caregivers who experienced few unmet needs opposed to the caregivers who experienced more unmet needs.

Conclusion: The current study provides an in-depth perspective on the caregiver's experiences and emphasizes specific themes that could be addressed in future interventions. This might contribute to a caring situation in which the caregiver experiences less unmet needs. Copyright (C) 2017 John Wiley \& Sons, Ltd.

Key words: young onset dementia; caregivers; service use; care needs

History: Received 11 October 2016; Accepted 18 May 2017; Published online 23 June 2017 in Wiley Online Library (wileyonlinelibrary.com)

DOI: $10.1002 /$ gps.4749

\section{Introduction}

Young onset dementia (YOD), defined as dementia with an onset before the age of 65 , causes specific challenges related to an earlier phase of life. For YOD caregivers, it can be difficult to find a balance between caring and their other responsibilities and roles in everyday life, such as being a parent, maintaining their social life and providing for their family. These caregiving responsibilities can be overwhelming, and caregivers often experience high levels of physical and psychological complaints and a low sense of competence in caring for their significant other (Millenaar et al., 2016b). This might result in particular needs and requirements for support and services. It is important to address these care needs, 
as unmet needs are associated with lower (health related) quality of life (Miranda-Castillo et al., 2010; Bakker et al., 2014), neuropsychiatric symptoms (Bakker et al., 2014) and earlier nursing home placement (Gaugler et al., 2005).

Therefore, the aim of this study is to investigate the needs caregivers of people with YOD face. The findings of this study together with the results of an earlier conducted literature review (Millenaar et al., 2016a) and focus groups with caregivers in several European countries will provide the basis for the development of an e-health intervention (the Research to Assess Policies and Strategies for Dementia in the Young project, RHAPSODY) to assist caregivers in coping with YOD (Kurz et al., 2016).

\section{Methods}

\section{Participants}

Qualitative interviews were used, which were conducted as part of the Needs in Young Onset Dementia (NeedYD) study in the Netherlands (van Vliet et al., 2010). All participants had a symptom onset before the age of 65 , and the dementia diagnosis was based on clinical, neuropsychological and neuroimaging data. Participants were excluded if there was no informed consent, if they were living in a nursing home or when the dementia was caused by something other than a neurodegenerative or vascular disorder.

In order to capture diverse caregiving settings, 20 interviews were selected based on the caregivers' ranking of unmet needs. All 209 caregivers were assessed with the Camberwell Assessment of Needs in the Elderly (Reynolds et al., 2000), which covers social, physical, psychological and environmental needs of the person with dementia (pwd) with a distinction between met and unmet needs. A random selection of the highest (95th) and the lowest (5th) percentile was made.

\section{Data collection}

The medical ethics committee of the Maastricht University Medical Centre approved the protocol of the NeedYD study. An interview guide (Appendix I) was composed from topics derived from relevant literature and clinical practice. The interviews were conducted at the caregivers' homes and audiotaped. In addition, caregiver and pwd characteristics were inventoried, including age, gender, education, relationship, dementia type, disease duration from symptom onset to study inclusion and dementia severity, assessed with the Global Deterioration Scale, which was divided in low (1-4), middle (5) and high (6-7) (Reisberg et al., 1982).

\section{Data analysis}

The interview audiotapes were transcribed verbatim and independently analysed by two researchers (JM and $\mathrm{CB}$ ). Through inductive content analysis (Elo and Kyngäs, 2008), both researchers independently coded caregivers' narratives and divided the content into higher order themes, moving from specific data to general findings. After assigning the codes, it was revealed which caregivers experienced a low amount of unmet needs and which had high numbers of unmet needs. To illustrate the results, quotations were used from the interviews. Each quotation is marked with a number indicating the specific caregiver and whether this caregiver experienced high levels of unmet needs $(\mathrm{H})$ or no unmet needs (L).

\section{Results}

\section{Participants}

After 18 transcripts, no new information emerged, indicating data saturation (Guest et al., 2006). Table 1 shows the baseline characteristics of the two groups. Participants in the group with high levels of unmet needs scored 8 to 13 items on the Camberwell Assessment of Needs in the Elderly as unmet, and in the other group, no unmet needs were reported. The group with low unmet needs consisted only of spouses, while in the high unmet needs group, half of the caregivers were spouses and the rest were friends or children. There were no other significant group differences.

\section{Interviews}

The analysis resulted in six major themes: (i) acceptance; (ii) perception of the relationship; (iii) role adaptation; (iv) Availability of appropriate services; (v) social support; and (vi) awareness in the pwd and acceptance of help. Figure 1 shows a schematic representation of the themes in the interviews. 
Table 1 Participant characteristics

\begin{tabular}{|c|c|c|c|c|}
\hline & $\begin{array}{c}\text { Total } \\
(N=18)\end{array}$ & $\begin{array}{l}\text { No unmet needs } \\
\quad(N=10)\end{array}$ & $\begin{array}{l}\text { High unmet } \\
\text { needs }(N=8)\end{array}$ & Test value \\
\hline Age, mean (SD) & $58.7(8.4)$ & $59.9(6.9)$ & $57.06(10.35)$ & $t(16)=.7$ \\
\hline Female, $n(\%)$ & $9(50)$ & $4(40)$ & $5(62)$ & $\chi^{2}(1)=.9$ \\
\hline \multicolumn{5}{|l|}{ Education, $n(\%)$} \\
\hline Low & 8 (44.4) & $4(40)$ & $4(50)$ & \multirow[t]{3}{*}{$\chi^{2}(2)=.3$} \\
\hline Medium & $6(33.3)$ & $4(40)$ & $3(38)$ & \\
\hline High & $3(16.7)$ & $2(20)$ & $1(12)$ & \\
\hline \multicolumn{5}{|l|}{ Diagnosis pwYOD, $n(\%)$} \\
\hline$A D$ & $8(44.4)$ & $5(50)$ & $3(38)$ & \multirow[t]{5}{*}{$\chi^{2}(4)=3.0$} \\
\hline FTD & $3(16.7)$ & $2(20)$ & $1(12)$ & \\
\hline VD & $3(16.7)$ & $2(20)$ & $1(12)$ & \\
\hline Lewy body & $2(11.1)$ & $0(0)$ & $2(25)$ & \\
\hline Mixed dementia (AD, VD) & $2(11.1)$ & $1(10)$ & $1(12)$ & \\
\hline Disease duration in years, mean (SD) & $7.0(3.6)$ & $7.5(2.4)$ & $6.4(4.9)$ & $t(16)=.6$ \\
\hline \multicolumn{5}{|l|}{ GDS, $n(\%)$} \\
\hline Mild & $9(50)$ & $6(60)$ & $3(38)$ & \multirow[t]{3}{*}{$\chi^{2}(2)=2.6$} \\
\hline Moderate & $4(22.2)$ & $3(30)$ & $1(12)$ & \\
\hline Severe & $4(22.2)$ & $1(10)$ & $3(38)$ & \\
\hline \multicolumn{5}{|l|}{ Relationship, $n$ (\%) } \\
\hline Partner & $14(77.8)$ & $10(100)$ & $4(50)$ & \multirow{3}{*}{$\chi^{2}(2)=6.4^{\star}$} \\
\hline Child & $2(11.1)$ & $0(0)$ & $2(25)$ & \\
\hline Friend & $2(11.1)$ & $0(0)$ & $2(25)$ & \\
\hline
\end{tabular}

Notes: $n$, number of subjects; SD, standard deviation; AD, Alzheimer's disease; FTD, frontotemporal dementia; VD, vascular dementia; GDS, Global Deterioration Scale.

*Indicates $p$-value $<0.05$.

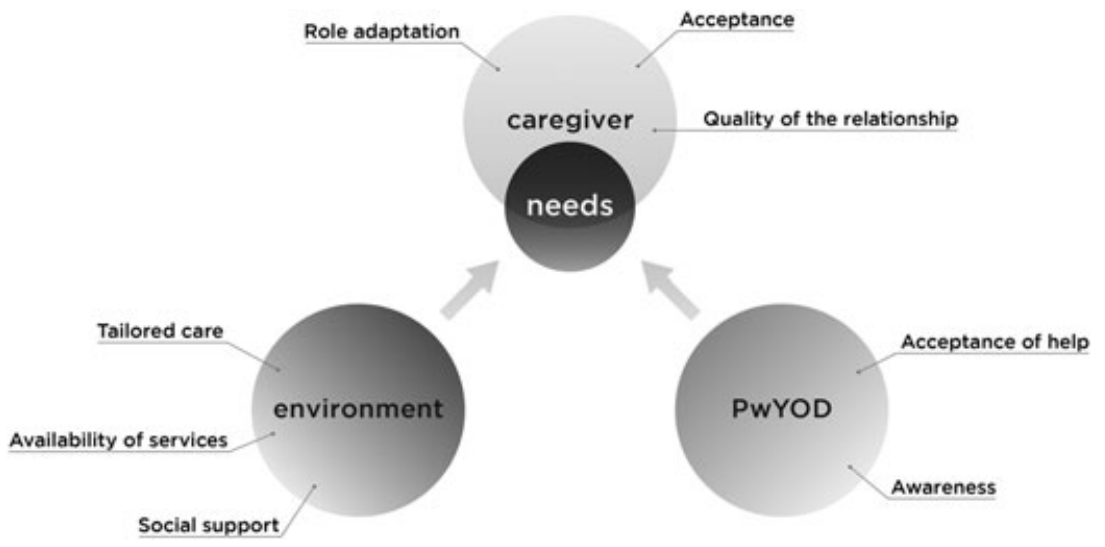

Figure 1 Schematic representation of the themes.

\section{Acceptance}

The process of accepting the diagnosis and its consequences, such as changes in daily life and the adjustment of future perspectives, was a reoccurring theme in the interviews. The time to diagnosis was often perceived as very problematic and seen as a long and stressful process. Because of the young age, professionals were less inclined to think about the possibility of a dementia diagnosis. Therefore, by the time the diagnosis was finally made, several caregivers perceived it as a relief because they finally knew what was going on and their worries were acknowledged and confirmed. This was explicitly stated by almost all caregivers who expressed no unmet needs.

If they would not have found anything, then there was no hope for me to continue the way we were going (...) So the diagnosis was the final missing piece of the puzzle (caregiver 7, L).

I was relieved something was going on, that I was right. We had fought for years (caregiver 15, L).

The other caregivers had more difficulties with accepting the diagnosis and its severity. 
It was very frightening and sad (..) just impossible to comprehend (caregiver 11, H).

You doubt if the diagnosis is correct (..) you ask yourself if you are too focussed on the mistakes (caregiver 2, H).

After receiving the diagnosis, the caregivers that struggled with the diagnosis had difficulties with accepting the changes. One caregiver explained that because of her young age, she still had a lot of future plans that she had to let go now.

I was still thinking about looking for another job, or doing a second study, or starting something new (....) we are in the life phase that we could go travel, we have the time and the means, but now we can't (...) Up until that moment you think everything is possible (caregiver $4, \mathrm{H}$ ).

The group that experienced no unmet needs seemed to be more able to accept these changes and the future.

Your whole life changes, for example you never expected to quit work so early. It's just that everything is different. (...) But that does not mean it's not good. I see the pleasant side of it (caregiver 1, L).

I can't be sorrowful, even though I wanted it to be different. I only take it one week at a time (caregiver 6, L).

\section{Quality of the relationship}

The dementia diagnosis caused major changes in the relationship between the caregiver and the pwd. Gradually, the pwd became more withdrawn and less concerned about the people around them. Caregivers talked about missing their comrade, decreasing intimacy and reciprocity and changes in the original role division. Particularly, in the high unmet needs group, the caregivers seemed more focused on the things they had lost in their relationship. They found it difficult to handle these changes and worried that it would get worse.

I realize it is a constant battle; you are not on the same level anymore. It feels like you are taking care of a stubborn child (caregiver 2, $\mathrm{H}$ ).

Nothing fun ever happens anymore. Some days there is only conflict and anger and we never laugh (...) We've had 25 good years but there are only bad years ahead of us (caregiver 4, H).
In the no unmet needs group, caregivers were more able to find a new balance within the relationship and to adjust their expectations.

We try to go on in the way we always have, of course you have to adjust to issues if they come in your path but for now we don't experience many problems (caregiver 14, L).

Sometimes I think our relationship became better. Now we are more aware of what we are doing and enjoy each other more. (..) before we were more concerned about work and such things, and that changed (caregiver 1, L).

\section{Role adaptation}

The caregivers explained how the dementia diagnoses affected their daily lives and how they struggled to combine caring with their other responsibilities. Because of the increasing demands in caring, they often started working less and missed their jobs and colleagues. Furthermore, their social life became less active and some caregivers felt isolated from their friends and family.

When I come home from work I'm so tired. But that just isn't an option, because someone is standing there who is dependent on you (caregiver 4, H).

We used to have a whole house full of friends and my husband used to be very social and invited everyone to our home. We both enjoyed it very much but it just isn't like that anymore. (caregiver 12, H).

The way caregivers dealt with these changes differed between the two groups. Especially, the caregivers without unmet needs focused on the aspects in their life that were still possible and believed it was better to live in the present instead of worrying. They accepted that their lives had changed and adjusted accordingly with a realistic view.

You have to stay positive, there are so many things that can still be nice. We are not able to do the thing we used to so now we do different things but it can be just as good. If you start to think in a negative way you have nothing to live for anymore (caregiver 1, L).

On the contrary, many of the caregivers in the high unmet needs group were very worried about the future and struggled with the responsibilities.

I have to do it all by myself. I have to decide what will happen to him. Could you imagine how that feels? Deciding about someone else life ... (caregiver $8, \mathrm{H}$ ). 
I do not want to think about the future (caregiver $2, \mathrm{H})$.

In most caregivers, the person with YOD was their absolute priority and they adapted a big part of their life to the pwd's needs. Almost everyone in both groups expressed the desire to take care of the person with YOD by themselves for as long as possible. However, most caregivers had difficulties delegating the care for different reasons such as distrust in the available services, feelings of shame or guilt or resistance of the person with YOD to accept care from others.

The difference between the two groups was the way the caregivers coped with the situation. In the group without unmet needs, the caregivers were better in determining their boundaries, for example, with respite care and realizing that they had to hand over the care eventually. In addition, they more often felt competent in dealing with the caregiving situation and finding their way within the care system. The caregivers from the high unmet needs group seemed to have more difficulties in balancing the care with their own lives and asking for help when necessary.

\section{Availability of appropriate services}

There was a lot of variability in the amount of help the participants received during the course of the disease and their experiences with the services available. Particularly, caregivers with high levels of unmet needs were not satisfied with the help they received and mentioned how they struggled to find the right services, to establish what care was necessary and how it could be arranged.

Psychologists did not have any experience with YOD, only with elderly people. So, we kept being send from pillar to post. It felt like we did not get any help (caregiver 2, H).

I think that the biggest problem for all of $u$ is to find our way. There is no instruction manual (caregiver $4, \mathrm{H}$ ).

Especially around the time of diagnosis, they experienced a lack of information and guidance. They sometimes felt that health care professionals were inconsiderate, did not take them seriously or did not offer the support they needed. This led to a general distrust of health care professionals and the postponement of the use of professional services and support.
They don't listen to me. They think they know best, because they work in health care. But I know better, because I have been caring for him for the past six years, $24 \mathrm{~h}$ a day (caregiver 8, H).

On the contrary, caregivers without unmet needs generally reported that they were satisfied with the amount and quality of information and guidance received. They described how the care and support were generally directed by a health care professional and tailored to their specific needs. These caregivers also reported that they knew where to ask for help when needed, even though they did not need help right now.

I know help is there when I need it, if it is to much they said she can be admitted for a week so I can go away by myself (...) it is good to know you have a safety net if something goes wrong (caregiver 13, L).

\section{Social support}

Many caregivers expressed the importance of open communication about the diagnosis and the difficulties they perceived. In this way, others knew what was going on and were able to provide a helping hand when needed. It was difficult for people around them to understand what it meant to have dementia at such a young age.

People do not understand what we are going trough (..). If you don't experience it yourself you can't comprehend what is happening to us (caregiver 6, L).

Particularly, in the no unmet needs group, many caregivers reported that they had friends or family around them who supported them.

We talk very openly about the disease within the family, it should not be a something that has to be difficult (caregiver $17, \mathrm{~L})$.

In the high unmet needs group, there were several caregivers who mentioned that they did not receive support from their friends and family and who felt like they were on their own.

I asked my sister if it would be possible if the family could meet us sometimes. Because I knew he would like that. But nobody ever comes (caregiver $8, \mathrm{H}$ ).

Some people just tell me, I don't think he has dementia (caregiver 2, $\mathrm{H}$ ). 


\section{Awareness in the pwd and acceptance of help}

When the pwd did not accept the diagnosis or was not aware of the difficulties the caregiver was facing, it was very difficult to arrange appropriate care. Specifically, the caregivers in the high unmet needs group described how the pwd was in denial. They tried to hide their problems and consequently refused help.

He tries to prove himself when he is with others, ten times a day he says 'you see I don't have Alzheimer's' (caregiver 2, H).

Refusal of the pwd to go to daycare costs a lot of energy for the caregiver to convince them to go or they felt guilty for forcing them to go.

She does not like day care. Sometimes she was standing next to the taxi screaming she didn't want to go. It breaks your heart to see her like that, so then I just let her stay with me (caregiver 3, H).

He does not want to go to day-care more than once a week, he feels he like he does not belong there and calls it a prison or a loony bin (caregiver 2, H).

A caregiver in the low unmet needs group talked about a specialized daycare for younger people, where his wife was actively involved in the daily activities. She liked going there, which made it a lot easier to gradually increase the amount of time she spends away from home.

At daycare there are younger people as well, which is much better. If she would have been there with elderly people who are just sitting there, she would not like it (caregiver 10, L).

\section{Discussion}

The aim of this study was to explore the needs and experiences of YOD caregivers by contrasting different perspectives. The analysis revealed that many caregivers in both groups were unhappy with the amount and quality of formal care and guidance they received, regardless of experienced unmet needs. This emphasizes the fact that only the number of services used is not indicative of unmet needs (MirandaCastillo et al., 2010). The difference between the two groups was that caregivers who did not express unmet needs had other ways to deal with their caregiving tasks despite the absence of (good) formal care.

Especially, acceptance of the diagnosis and the accompanying changes was a reoccurring theme in the interviews with the caregivers who did not express any unmet needs. This allowed them to adjust their expectations and to adapt to their new role as caregiver. However, in order to do so, adequate information about the diagnosis is necessary (Banerjee et al., 2007; Quinn et al., 2008; Boots et al., 2015). In addition, they were more focused on the aspects in their lives that were still possible rather than experienced losses. This is in accordance with previous studies showing that understanding and accepting the diagnosis leads to fewer difficulties in adjusting to changes (Banerjee et al., 2007) and allows caregivers to focus on possibilities (Boots et al., 2015).

Another factor that seemed to contribute to a caring situation with less unmet needs is the availability of social support. Caregivers emphasized the importance of openly communicating about the difficulties they were facing. The availability of social networks has been associated with less unmet needs (Miranda-Castillo et al., 2010). It is also shown that open communication is an important step in acquiring support from the environment. Caregivers are often hesitant to ask for help because they are afraid of burdening others or assume that people are reluctant to help. However, people around them are actually often willing to provide support but do not know how they can contribute or are afraid to violate their privacy or stigmatize the situation (Dam, Boots, Verhey, Boxtel and de Vugt, in press). Therefore, it is important that caregivers express their needs and experiences. Unfortunately, many people with YOD and their caregivers experience a sense of stigma and feel that they cannot share the diagnosis and accompanying problems with others around them (Ducharme et al., 2013).

Other factors that were more apparent in the caregivers that experienced less unmet needs were related to the pwd. Arranging the right care was easier when the pwd was aware of the diagnosis and accepted the consequences. However, younger carers not always share knowledge about the diagnoses or discuss it with the pwd (Lockeridge and Simpson, 2013) to protect the person with YOD. However, this might have negative consequences for their relationship because it can lead to conflict and loss of trust (Lockeridge and Simpson, 2013). Openly communicating about the disease seemed beneficial for arranging the right care because the pwd had more insight into his or her limitations and could be more involved in the necessary adaptations in life without resisting.

The current study has some limitations. First, results are based on proxy ratings, while it is known that the evaluation of unmet needs might differ from 
the perspective of the pwd. There is fair agreement about the areas in which needs occur, but caregivers seem to report more needs than the pwd themselves (Bakker et al., 2014). However, because the goal of this study was to provide input for the development of an educative intervention for caregivers, the use of proxy rated measurements seemed suitable. Secondly, caregivers who experienced more unmet needs were more often children and friends compared to the caregivers that did not express any unmet needs as they consisted of spousal caregivers only. The relationship to the care recipient might influence the caregiving experience, as spouses often view their role as caregiver as part of their marital duties (Conde-Sala et al., 2010). Furthermore, even though child caregivers often spend less time providing care, they seem to experience more burden than spousal caregivers (Reed et al., 2014). Third, the methodology of the current study is not suitable to establish significant predictors of unmet needs. There are probably more factors that influence the caring situation and the caregivers' capacity to demonstrate resilience. Further research is needed to gain more insight into the importance of aspects such as care recipient status, resources, caregiver management strategies, sense of competence, personality traits and coping styles for targeting and personalizing postdiagnostic interventions for carers.

The current study provides an in-depth perspective on the caregivers' experiences and needs that could be addressed in future interventions. Specifically, when dementia starts at a younger age, themes addressing acceptance and the experienced losses seem to carry additional weight compared to late onset dementia. These younger individuals might have had other expectations of the future and be more focused on what could have been if they would not have been a caregiver. This complicates adjusting to their new role as caregiver. Our findings emphasize the importance of support early on, in order to facilitate the acceptance process in the caregivers as well as the pwd. Interventions should focus on accepting the changes, adjusting expectations and focusing on the positive aspects of their lives rather than the experienced losses. In addition, it is important to encourage open communication within the social environment to allow others to provide support.

\section{Conflict of interest}

None declared.
Key points

- More appropriate help is needed after receiving the diagnosis.

- Acceptance is a prerequisite for adapting to the role of caregiver.

- It is essential to reinforce positive perceptions of the relationship between the caregiver and the care recipient.

\section{Acknowledgements}

We thank all researchers from the RHAPSODY consortium for their feedback and efforts to translate the findings into the online intervention. We thank the research assistants Yvette Daniels, Danique Hellebrekers and Kristy Hermans for transcribing the interviews. The NeedYD study was supported with a grant from the Dutch Alzheimer Society and a grant from the Florence Care Group in the Netherlands. The RHAPSODY project is an EU Joint Program Neurodegenerative Disease Research (JPND) project. The project is supported through the following funding organizations under the aegis of JPND (www.jpnd.eu). France: National Research Agency; Germany: Ministry of Education and Research; The Netherlands: The Netherlands Organization for Health Research and Development; Portugal: Foundation for Science and Technology; Sweden: The Swedish Research Council; United Kingdom: Economic and Social Research Council.

\section{References}

Bakker C, de Vugt ME, van Vliet D, et al. 2014. The relationship between unmet care needs in young-onset dementia and the course of neuropsychiatric symptoms: a two-year follow-up study. Int Psychogeriatr 26: 1991-2000.

Banerjee S, Willis R, Matthews D, et al. 2007. Improving the quality of care for mild to moderate dementia: an evaluation of the Croydon Memory Service Model. Int J Geriatr Psychiatry 22: 782-788.

Boots LM, Wolfs CA, Verhey FR, Kempen GI, de Vugt ME. 2015. Qualitative study on needs and wishes of early-stage dementia caregivers: the paradox between needing and accepting help. Int Psychogeriatr 27: 927-936.

Conde-Sala J, Garre-Olmo J, Turró-Garriga O, Vilalta-Franch J, López-Pousa S. 2010. Quality of life of patients with Alzheimer's disease: differential perceptions between spouse and adult child caregivers. Dement Geriatr Cogn Disord 29: 97-108.

Dam AEH, Boots LMM, van Boxtel MPJ, Verhey FRJ, de Vugt ME. in press. A mismatch between supply and demand of social support in dementia care: a qualitative study on the perspectives of spousal caregivers and their social network members. Int Psychogeriatr.

Ducharme F, Kergoat MJ, Antoine P, Pasquier F, Coulombe R. 2013. The unique experience of spouses in early-onset dementia. Am J Alzheimers Dis Other Demen 28: 634-641.

Elo S, Kyngäs H. 2008. The qualitative content analysis process. J Adv Nurs 62: $107-115$.

Gaugler JE, Kane RL, Kane RA, Newcomer R. 2005. Unmet care needs and key outcomes in dementia. J Am Geriatr Soc 53: 2098-2105.

Guest G, Bunce A, Johnson L. 2006. How many interviews are enough? An experiment with data saturation and variability. Field Methods 18: 59-82. 
Kurz A, Bakker C, Böhm M, et al. 2016. RHAPSODY-Internet-based support for caregivers of people with young onset dementia: program design and methods of a pilot study. Int Psychogeriatr 28: 2091-2099.

Lockeridge S, Simpson J. 2013. The experience of caring for a partner with young onset dementia: how younger carers cope. Dementia 12: 635-651.

Millenaar JK, Bakker C, Koopmans RT, et al. 2016a. The care needs and experiences with the use of services of people with young-onset dementia and their caregivers: a systematic review. Int J Geriatr Psychiatry 31: 1261-1276.

Millenaar JK, de Vugt ME, Bakker C, et al. 2016b. The impact of young onset dementia on informal caregivers compared to late onset dementia: results from the NeedYD study. Am J Geriatr Psychiatry 24: 467-474.

Miranda-Castillo C, Woods B, Galboda K, et al. 2010. Unmet needs, quality of life and support networks of people with dementia living at home. Health Qual Life Outcomes 8: 1.

Quinn C, Clare L, Pearce A, van Dijkhuizen M. 2008. The experience of providing care in the early stages of dementia: an interpretative phenomenological analysis. Aging and Mental Health 12: 769-778.

Reed C, Belger M, Dell'Agnello G, et al. 2014. Caregiver burden in Alzheimer's disease: differential associations in adult-child and spousal caregivers in the GERAS observational study. Dementia and Geriatric Cognitive Disorders Extra 4: 51-64.
Reisberg B, Ferris SH, de Leon MJ, Crook T. 1982. The Global Deterioration Scale for assessment of primary degenerative dementia. Am J Psychiatry 139: 1136-1139.

Reynolds T, Thornicroft G, Abas M, et al. 2000. Camberwell Assessment of Need for the Elderly (CANE) development, validity and reliability. Br J Psychiatry 176: 444-452.

van Vliet D, Bakker C, Koopmans RT, et al. 2010. Research protocol of the NeedYDstudy (Needs in Young onset Dementia): a prospective cohort study on the needs and course of early onset dementia. BMC Geriatr 10: 13.

\section{Supporting Information}

Additional Supporting Information may be found online in the supporting information tab for this article.

Appendix I. Individual interview 